\title{
Guangzhou Tongcao painting in late China Qing Dynasty (1840-1912 AD): technology revealed by analytical approaches
}

\author{
Chan Zhang ${ }^{1,2 \dagger}$, Jianbin Huang ${ }^{3 \dagger}$, Tiequan Zhu ${ }^{1,4,5^{*}}$ and Rongling Zhang ${ }^{6}$
}

\begin{abstract}
Guangzhou Tongcao paintings in Qing Dynasty of China witnessed the exchange of economy, culture, art and technology between China and foreign countries, which were an important export product in historical China. In this paper, by using Optical Stereo Microscope, Polarized Light Microscope, Scanning Electron Microscope attached Energy Dispersive Spectroscopy and micro confocal laser Raman Spectroscope, a Qing Dynasty Tongcao painting with the subject of family life of an official's female relative was analyzed. Our study revealed that: (1) the hexagonal cell morphology which was easily observed in the Tongcao pith could contain more pigments and increase the stereo sense of painting, and the cell of historical Tongcao pith had started to degrade, which indicated an urgent requirement on conservation of Tongcao paintings; (2) alum was needed as the fixing agent in the preparation of pigments and the painting process; (3) both the China domestic pigments including red lead, calcite, lead white, carbon black and gamboge, and the synthetic pigments imported from Europe (synthetic ultramarine, prussian blue and emerald green) were applied in this painting, which reflected the bi-directional communication of culture and technology between China and western world. Meanwhile, the existence of synthetic ultramarine, prussian blue and emerald green was helpful to further identify the production date of this painting was late Qing Dynasty, mainly the mid-late 19th century.
\end{abstract}

Keywords: Tongcao painting, Cell morphology, Alum, Pigment, Technology, Culture

\section{Introduction}

Tongcao (通草) paintings, which were painted directly on Tongcao pith (the stem of Tetrapanax papyriferus without any chemical treatment), were a kind of export watercolor painting. They were produced mainly in late Qing Dynasty of China (1840-1912AD) in Guangzhou, and yet specially sold to European. As Tongcao paintings imitated western painting style to some extent and vividly recorded nearly all aspects of local customs of Guangzhou at that time, they were favored by foreigners once

\footnotetext{
*Correspondence: 46380080@qq.com

${ }^{\dagger}$ Chan Zhang and Jianbin Huang contribute equally to this work, and they are both the first authors.

${ }^{1}$ Research Center for Visual Culture, Guangzhou Academy of Fine Arts, Guangzhou 510006, China

Full list of author information is available at the end of the article
}

they were created. Almost every foreigner would buy and bring them to his homeland to share with his friends and families what they saw in Guangzhou before the invention of camera, so they also had another name of Guangzhou Postcard. As a representative export painting from Guangzhou in the 19th century, Tongcao paintings were a vivid reflection on the integration of trade, culture and art between China and the West along the Maritime Silk Road. Therefore, for a long time they were focused by experts in different fields, including history, archaeology, art and so on.

As early as 1970s-1990s, American scholar Carl L. Crossman studied the creation and trade transmission of Tongcao paintings $[1,2]$. Since that time, more and more attention had been paid to this special kind of painting. In 2007, professor Jiang of Sun Yat-sen University tried to
Springer Open

(c) The Author(s) 2021. This article is licensed under a Creative Commons Attribution 4.0 International License, which permits use, sharing, adaptation, distribution and reproduction in any medium or format, as long as you give appropriate credit to the original author(s) and the source, provide a link to the Creative Commons licence, and indicate if changes were made. The images or other third party material in this article are included in the article's Creative Commons licence, unless indicated otherwise in a credit line to the material. If material is not included in the article's Creative Commons licence and your intended use is not permitted by statutory regulation or exceeds the permitted use, you will need to obtain permission directly from the copyright holder. To view a copy of this licence, visit http://creativeco mmons.org/licenses/by/4.0/. The Creative Commons Public Domain Dedication waiver (http://creativecommons.org/publicdomain/ zero/1.0/) applies to the data made available in this article, unless otherwise stated in a credit line to the data. 
study Tongcao paintings in the context of port history [3], which aroused a tremendous interest on such painting among Chinese scholars. Later in 2008, professor Cheng focused on the manufacture technique of Tongcao pith and development of Tongcao paintings in different periods [4], whose research became the first monographic study of Tongcao paintings in China. Meanwhile, some western scholars carried a series of researches to explore the reparation and conservation of Tongcao paintings from the usage of new reparation materials, treatment methods \& specific operation, and the control of storing environment $[5,6]$. In 2014, basing on the images of Tongcao paintings, Patrick Conner fully studied the style and feature of Thirteen Hongs commercial area along the Pearl River in Guangzhou [7]. In the same year, Ifan Williams and Cheng Meibao cooperatively published a book, where all the Tongcao paintings from 29 museums and galleries of the world were systemically sorted and classified according to their content and subjects [8]. Furthermore, Guangzhou Thirteen Hongs Museum (a museum collecting historical artifacts of Thirteen Hongs, which was the monopoly organization managing the foreign trade in Guangzhou appointed by Qing government) published a book to show abundant exquisite Tongcao paintings stored in its museum, which demonstrated a great deal of historical information of historical Guangzhou [9].

Overall, the study of Tongcao paintings was still in the early phase and principally relied on methods like Iconography and the analyses of historical documents, where scientific studies were very rare. As Tongcao paintings combined selection and cutting of Tongcao pith, treatment of alum, painting and other techniques, they partly reflected the technological complexity of folk painting in Guangzhou at that time. Given these considerations, the attempt to comprehensively analyzed representative Tongcao paintings samples from a technological perspective was required to disclose the materials and drawing procedure of such painting. Not only would these studies bring new insights into techniques that produced Tongcao paintings, but they were also helpful to understand the technical decisions made by craftsmen basing on the background of economy, culture and art in late Qing Dynasty. Technical analyses on Tongcao paintings had more practical impact that provided the scientific foundation of preserving and restoring this kind of painting.

In this paper, we analyzed a historical Tongcao panting by using Optical Stereo Microscope (OM), Polarized Light Microscope (PLM), Micro Confocal Laser Raman Spectroscope ( $\mu-\mathrm{RS})$, and Scanning Electron Microscope with Energy Dispersive X-ray Spectrometer (SEM-EDS). Basing on the analyses, we attempted to reveal, from a technological perspective, what kinds of materials and how they were prepared in the whole manufacturing process of Tongcao paintings. Meanwhile, we discussed the types of pigments (both domestically produced in China and the imported) used in this painting, which could throw a light on exploring the cultural and technological communication between China and Europe.

\section{Materials and methods Sampling \\ The historical Tongcao painting}

The historical Tongcao Painting was kindly provided by the Anthropology Museum of Sun Yat-sen University. It depicted a scene that a senior official lady of imperial court was appreciating flowers accompanied by a maid (Fig. 1), and the painting was applied with different kinds of colors including blue, green, yellow, red, white and black. Not only this painting was rich in colors and of exquisite image, meaning the complexity of manufacturing technique, but such kind of subject was universal in Tongcao paintings and welcomed by foreigners at that time, so it was a representative piece at that time. However, it was a pity that the information about its

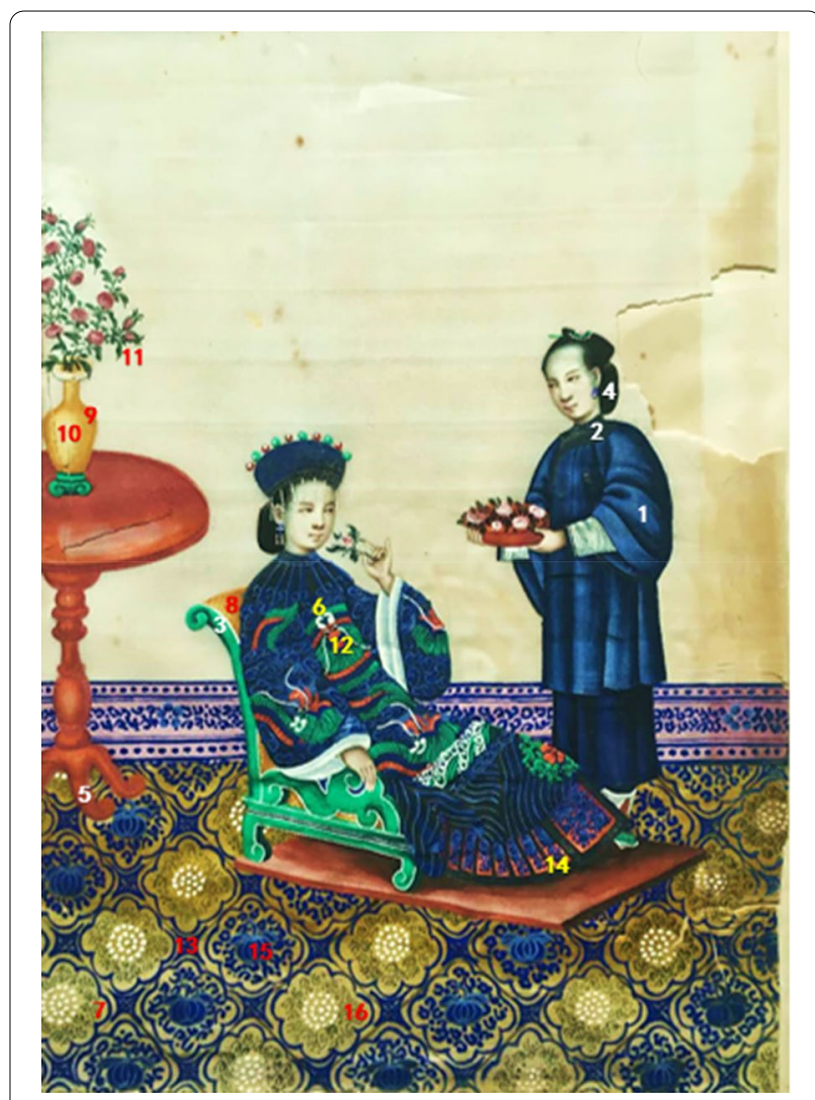

Fig. 1 Guangzhou Tongcao painting of late Qing Dynasty of China 
production year appeared on the tag of the painting was absent, which brought difficulty for us to judge its specific production date. Therefore, it was generally identified to be an artwork of late Qing Dynasty (1840-1912AD) based on conventional view.

The detection points of number 1 to 16 were selected for Raman spectrum analysis nondestructively (Fig. 1), whose details could be seen in Table 1, including the areas and colors they referred to.

\section{Tongcao pith of 2015}

The Tongcao pith produced in Guizhou province in 2015 was collected and cut into several pieces (respectively named as $\mathrm{x}_{0}, \mathrm{x}_{1}, \mathrm{x}_{2}, \mathrm{x}_{3}$ ) for simulative experiments.

According to the records of The Painting Manual of the Mustard Seed Garden (芥子园画传) [10], we prepared the solution of gelatin and alum in ratio of 7:3, which was then coated on $x_{0}$ for 0 times, $x_{1}$ for 4 times, $x_{2}$ for 8 times and $x_{3}$ for 12 times for SEM-EDS analyses. Meanwhile, the unpainted piece (named as $\mathrm{q}_{0}$ ) and coloring pieces (respectively named as $\mathrm{q}_{1}$ and $\mathrm{q}_{2}$ ) of the historical painting were served as compared samples.

\section{Analytical facility \\ Microscopy}

A RH-2000 optical stereo microscope (Japan) with multiple range of $35-2500 \times$ was used to in situ and nondestructively observe the microscopic state of cells and pigments of samples. As configured with Hirox software

\section{Table 1 Basic information of 16 detection points for Raman spectroscopy}

\begin{tabular}{lll}
\hline Number & Detection area & Color \\
\hline 1 & Maid's sleeve & Light blue \\
2 & Maid's collar & Deep blue \\
3 & Back of chair & Bright green \\
4 & Maid's hair & Black \\
5 & Table leg & Orange red \\
6 & The horn of dragon pattern on hostess's gown & White \\
7 & Decorative pattern of floor & Light yellow \\
8 & Back of chair & Yellow \\
9 & The edge of vase & Deep yellow \\
10 & The center of vase & Light yellow \\
11 & Leaves of flowers in vase & Dark green \\
12 & The mouth of dragon pattern on hostess's & Red \\
& gown & \\
13 & Decorative pattern of floor & Blue \\
14 & The lower hem of hostess's gown & Red \\
15 & Decorative pattern of floor & Blue \\
16 & Decorative pattern of floor & Yellow \\
\hline
\end{tabular}

system, not only could this microscope capture the highdefinition image in real time, but it was able to synthesize the image in 3D.

A Polarized Light Microscope (ortholux11PPL-BK, Leitz, Germany) was used to check the purity, shape and size of blue particles which were separated from a fragment of the historical Tongcao painting, helping to identify the composition of blue pigment.

\section{Micro confocal laser raman spectroscopy}

The Renishaw Invia laser Raman spectroscope (Gloucestershire, UK) was chiefly employed to analyze phase structure of different pigments on the painting, which used argon ion laser as light source, with an excitation wavelength of $785 \mathrm{~nm}$, an objective lens of 50x, a spot size of $1 \mu \mathrm{m}$ and a spectral resolution of $1 \mathrm{~cm}^{-1}$. Raman spectra were recorded in wavenumber mainly between 100 and $3000 \mathrm{~cm}^{-1}$, with spectral accuracy of about $1 \mathrm{~cm}^{-1}$. An optical microscope was used to focus the laser on samples, at $\times 50$, throughout the analysis. Calibration was carried out on the Raman spectrometer on a daily basis using the Raman signal of silicon at $520 \mathrm{~cm}^{-1}$. Background spectra of water and carbon dioxide were obtained in ambient air. Raman spectra presented here were smoothed without baseline correction.

\section{Scanning electron microscope with energy dispersive X-ray spectrometer}

Equipped with INCA X-ray spectrometer (EDX, Oxford, UK)), The Quanta-400F thermal field environment scanning electron microscope (ESEM, Philips, the Netherlands) was used to analyze the micro structure and composition of samples, with the experimental voltage of $20 \mathrm{kv}$ and the mode of low vacuum, under which the pressure of sample chamber was $60 \mathrm{~Pa}$. By using this machine, the very small pieces fell down from the painting, as well as the Tongcao pith of 2015 were collected and analyzed.

\section{Results and discussion} The Tongcao pith

As the carrier of Tongcao Paintings, Tongcao pith, with the yellowish white appearance, was cut from the stem of Tetrapanax papyriferus, which were usually planted in southern China like Guizhou, Fujian, and Taiwan. In Qing Dynasty, Tongcao was recorded to be used in painting by craftsmen in Guangzhou.

It was well kown that Tongcao pith had not been treated by any chemical process, and its hexagonal cell structure could be clearly seen under the microscopy (Fig. 2), which differentiated from that of Xuan paper with numerous and various sizes of fibers mixed together irregularity. Under the SEM-EDS, surface of Tongcao pith looked like the honey honeycomb, which was helpful 

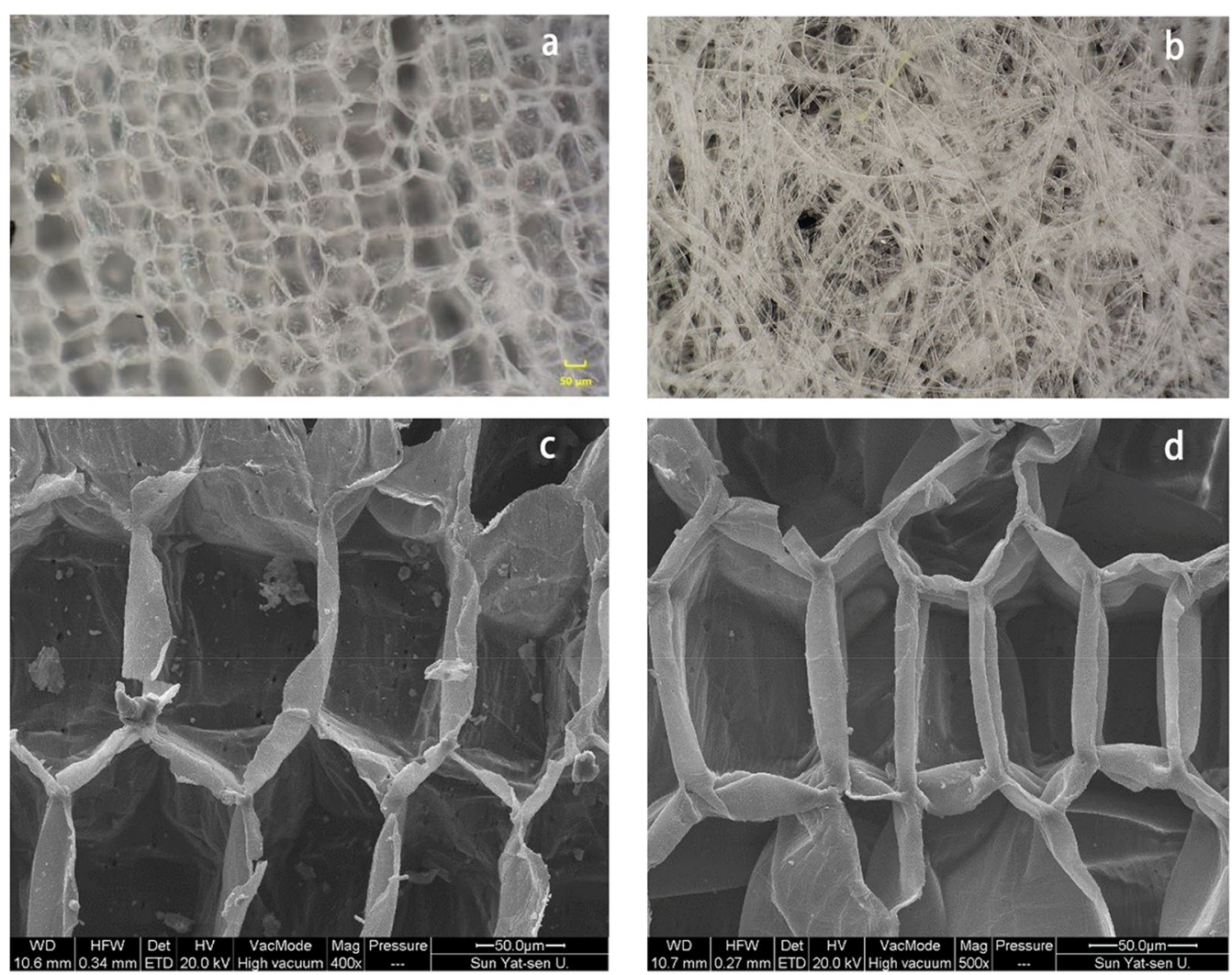

Fig. 2 Microscopic comparison between: a Tongcao pith and $\mathbf{b}$ Xuan paper under OM; $\mathbf{c}$ the unpigmented area of ancient Tongcao painting and $\mathbf{d}$ modern Tongcao pith under SEM-EDS

for the stack of pigments and formed an uneven surface for the distribution of pigments, so Tongcao paintings looked stereoscopic and colorful. Generally, the cell wall of plants mainly consisted of cellulose micro fibrils, lignin, hemicellulose and a few pectin as well as glycoprotein [11]. There were special cross-linked substance among these components, which enabled the cell wall to own enough mechanical strength in all directions, providing source for the structural support of Tongcao pith. However, compared with microstructure of Tongcao pith produced in 2015, cells of the historical painting had changed in their shape, which suggested the start of degradation of secondary cell wall. Meanwhile, the connection among cell walls seemed very loose in the painting, which directly led to the strength reduction of its mechanical support and eventually resulted in the rupture and smash of Tongcao pith. Therefore, the correlating conservation work of Tongcao paintings needed to be carried out emergently.

\section{The usage of alum in Tongcao painting}

The alum glue, a kind of solution which mixed the alum and gelatin, was chiefly used as an adhesive in the process of drawing, mounting and repairing of painting and calligraphy [12], which on one hand could enhance the binding force among plant fibers, and on the other hand, had the function of fixing pigments, keeping painting brightcolored, enhancing water resistance of paper and inhibiting growth of microorganism. In the mid-19th century, British traveler Downing once recorded in his travel notes the making and drawing procedure of Tongcao paintings in detail as followed:

The paper being ready, it is washed over with a weak solution of alum, as they consider it is thus rendered more fit to receive the colors. This wash is frequently repeated during the progress of the work, so that before it is finished, it has received seven or eight coats. It is difficult at first to conceive the utility of the alum, but upon reflection it appears to me, that it is this mineral which gives such a degree of permanence to the coloring of the Chinese [13].

Since the drawing technique of Tongcao paintings had been lost, whether alum glue had been applied in the manufacture process of Tongcao paintings was a controversial question. In order to solve this question, we 
compared the chemical difference among Tongcao pith with and without alum glue treated, and both pigments area and unpigmented area of the historical painting.

The chemical formula of alum was $\mathrm{KAl}\left(\mathrm{SO}_{4}\right)_{2} \cdot 12 \mathrm{H}_{2} \mathrm{O}$. As shown in Table 2 and Fig. 3, the chemical difference among samples was mainly on the elements $\mathrm{Al}$ and $\mathrm{S}$. It was easy to find that with the increase of coating times, content of $\mathrm{Al}$ and $\mathrm{S}$ were on an increasing tendency, indicating the higher concentration of alum. However, they basically stopped increasing when the number of coating times was over 8 , revealing the adsorption capacity of cells tended to be saturated. On the other hand, content of $\mathrm{Al}$ and $\mathrm{S}$ remained in $\mathrm{q}_{0}, \mathrm{q}_{1}$ and $\mathrm{q}_{2}$ apparently exceeded than that of $x_{0}$, relatively close to $x_{1}$ or $x_{2}$, which proved alum was applied both in the unpainted area and pigments area of the historical Tongcao painting. These findings were basically in accord with Downing's record.

\section{The pigments}

In China, the archaeological evidence revealed that as early as the Shan dingdong Man archaeological site (30,000-40,000 years ago), hematite was ever used as the red pigment in burial area of this archaeological site. Subsequently, more and more types of pigments were used to paint the life of historical human being. The pigment itself not only recorded ancestor's knowledge of natural pigments including all kinds of mineral powder and plant dyes, but also memorized the new invention of artificial synthesis pigments. In addition, pigment also witnessed historical trade and technological transmission. Our studies disclosed the following pigments were applied in the historical Tongcao painting.

\section{The black pigment}

Figure 4a was the Raman spectrum of black pigment, where Raman peaks of 1324 and $1596 \mathrm{~cm}^{-1}$ were

Table 2 Semi quantitative analysis results of SEM-EDS(wt \%)

\begin{tabular}{llllllll}
\hline Samples & $\mathbf{X}_{\mathbf{0}}$ & $\mathbf{X}_{\mathbf{1}}$ & $\mathbf{X}_{\mathbf{2}}$ & $\mathbf{X}_{\mathbf{3}}$ & $\mathbf{Q}_{\mathbf{0}}$ & $\mathbf{Q}_{\mathbf{1}}$ & $\mathbf{Q}_{\mathbf{2}}$ \\
\hline $\mathrm{Al}$ & 0.06 & 0.22 & 0.44 & 0.38 & 0.17 & 0.12 & 1.43 \\
$\mathrm{~S}$ & 0.07 & 0.32 & 1.14 & 1.13 & 0.10 & 0.26 & 0.85 \\
$\mathrm{~K}$ & 0.15 & 0.19 & 0.14 & 0.16 & 0.17 & 0.11 & 0.18 \\
$\mathrm{~Pb}$ & $/$ & $/$ & $/$ & $/$ & $/$ & 2.1 & 1 \\
$\mathrm{Ca}$ & 1.05 & 0.64 & 0.69 & 0.57 & 2.32 & 1.14 & 2.84 \\
\hline
\end{tabular}

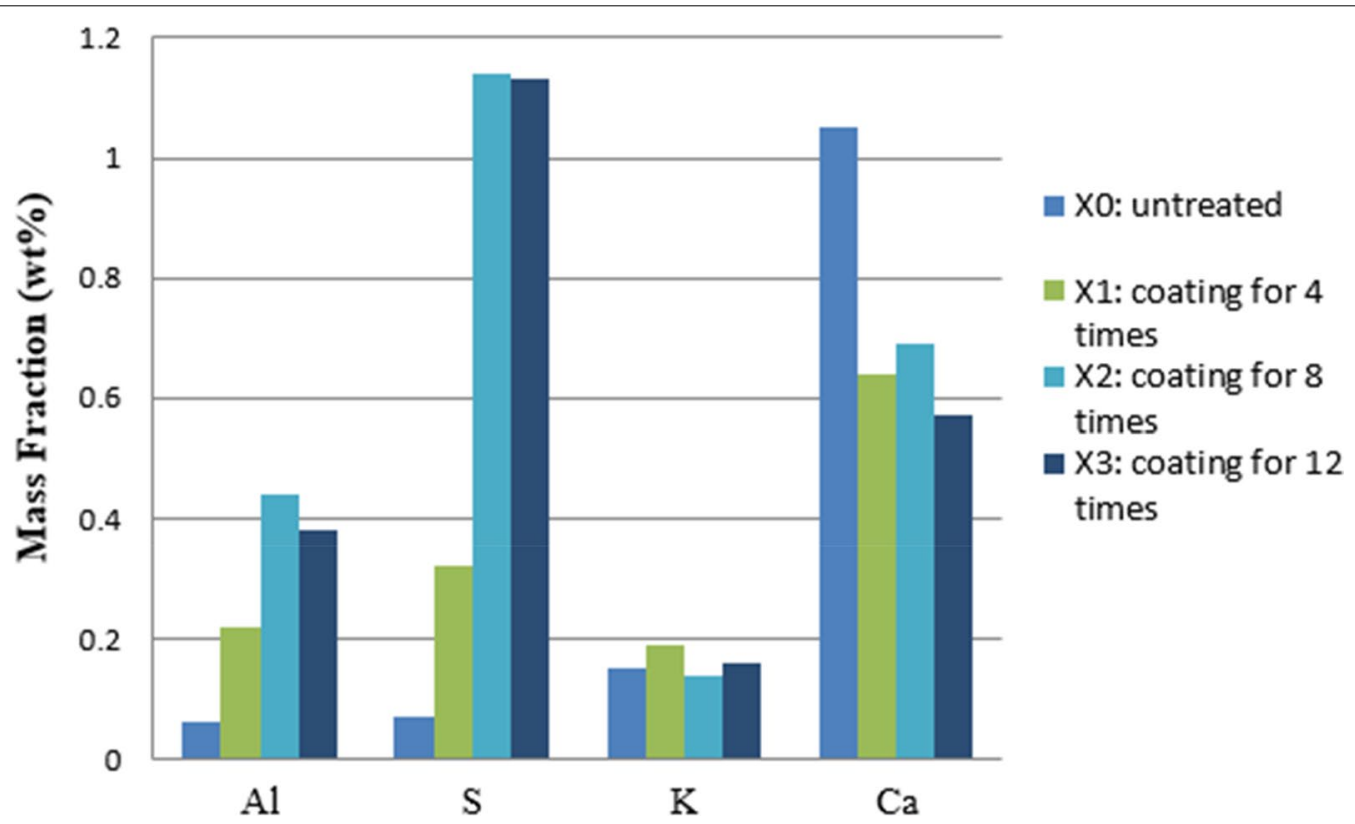

Fig. 3 The chart of elemental concentration in modern Tongcao pith with different treatment 


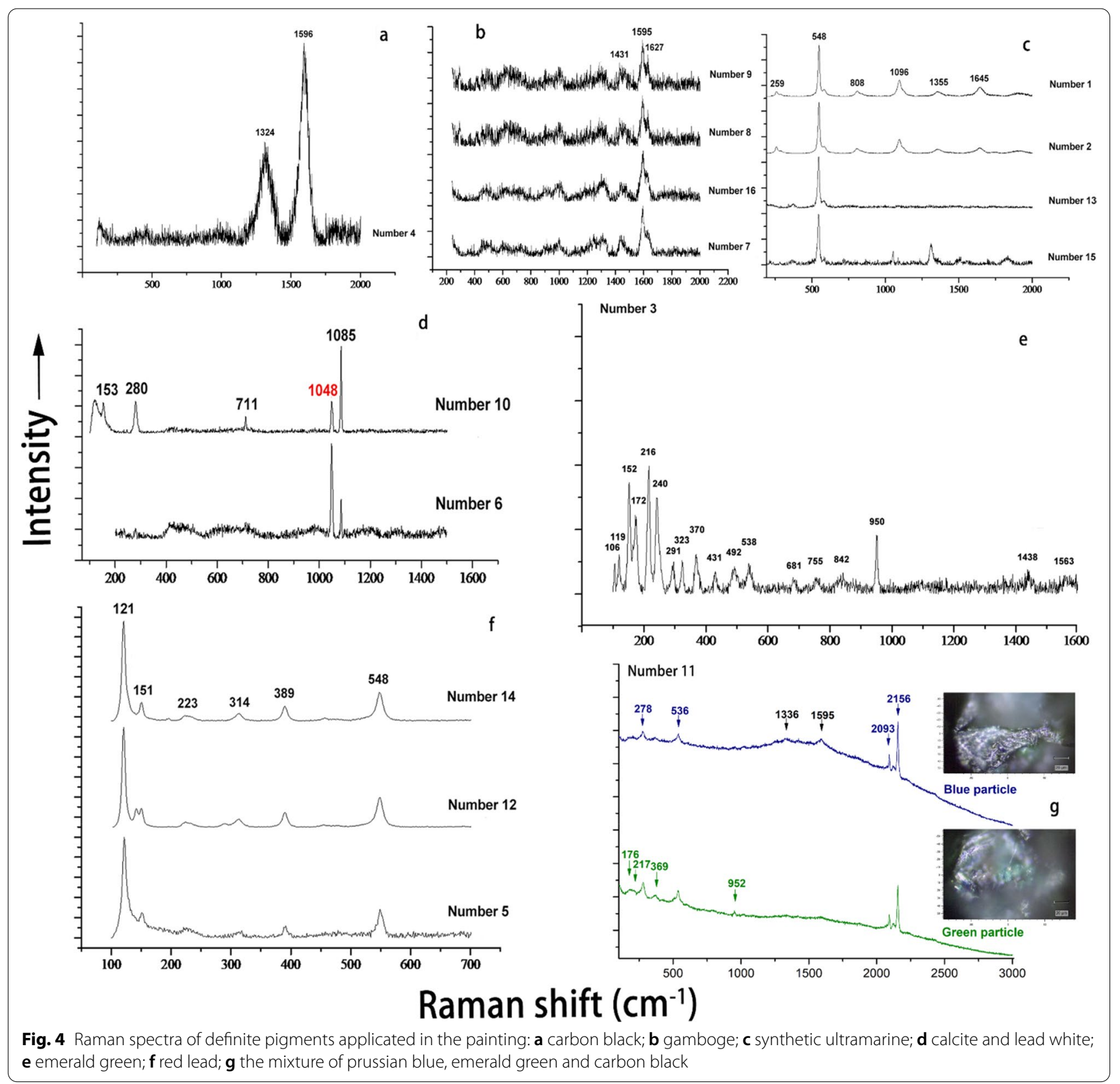

basically consistent with carbon black [14]. As we knew, Carbon black was black outside appearance with particle size of 30-40 $\mu \mathrm{m}$, and was a kind of amorphous graphite, which was usually applied as black pigment in historical China.

\section{The white pigment}

As shown in Fig. 4d, the Raman peaks of 153, 280, 711 and $1085 \mathrm{~cm}^{-1}$ were consistent with calcite [15], while that of $1048 \mathrm{~cm}^{-1}$ was the characteristic peak of lead white [16]. Therefore, two white pigments (calcite and lead white) were used both in these areas. Surprisingly, judging from the intensity of Raman shifts at $1048 \mathrm{~cm}^{-1}$ and $1085 \mathrm{~cm}^{-1}$, it was easily to conclude that the proportion of calcite and lead white used as the white pigments in different areas were different. As we knew, lead white had better whiteness and coverage, so when painting the area of white dragon pattern (Number 6), the artist specially selected the higher proportion of lead carbonate as the white pigment to protrude the dragon and meanwhile, more lead carbonate could reduce the interference effect of blue pigment under it. 


\section{The yellow pigment}

Serial Raman peaks of 1431, 1595 and $1627 \mathrm{~cm}^{-1}$ (Fig. 4b) demonstrated the existence of gamboge [16] in different tested areas of Number 7, 8, 9 and 16. Gamboge was a kind of gelatinous resin secreted by plant of gamboge, mainly planted in India, Vietnam and Thailand. The earliest archaeological case of gamboge as a yellow pigment in China was the wooden objects unearthed from the tomb of Astana in Xinjiang province, which could date back to Tang Dynasty [17].

\section{The red pigment}

Figure $4 \mathrm{f}$ showed that the spectra of three detection points (Number 5, 12 and 14) were basically the same. Serial Raman peaks of 121, 151, 223, 314, 389 and $548 \mathrm{~cm}^{-1}$ referred to red lead [16], whose main component was lead tetroxide $\left(\mathrm{Pb}_{3} \mathrm{O}_{4}\right)$. The used of red lead could date back to Eastern Han Dynasty of China, which was introduced from the West via the Silk Road [18]. Because there was extremely few red lead in natural minerals, red lead was generally produced by certain processes, no matter in historical times or modern times. It was a kind of pigment universally used in Chinese artworks, the color of which varied from orange to red depending on its purity [19].

\section{The blue pigment}

It was clearly seen in Fig. 4c that Raman spectra of four detection points numbered 1, 2, 13 and 15 were basically the same, where Raman peaks of $259,548,808,1096$, 1355 and $1645 \mathrm{~cm}^{-1}$ referred to ultramarine blue [20]. Nevertheless, there were two kinds of ultramarine blue: the natural form extracted from Lapis lazuli and the synthetic form first synthesized by Jean Baptiste Guimet in 1828, a French industrial chemist [21]. In recent years, researchers had used SEM-EDS, FITR, $\mu$-Raman and other methods to find out there were some characteristic peaks of 156, 283, 713 and $1086 \mathrm{~cm}^{-1}$ belong to the calcite component in blue particles of natural ultramarine, which were absent in synthetic ultramarine [22]. To further support this, we separated some blue pigments from a fragment of this painting, treated them with absolute alcohol and filtered out the scattered blue particles on glass slides. Under the polarized light microscope, the majority of particles were round and homogeneous with diameter of 2-4 $\mu \mathrm{m}$, and meanwhile, they were pure in deep blue color (Fig. 5), whose characteristic were closer to synthetic ultramarine [23].

Compared with natural ultramarine, the price of synthetic ultramarine was cheaper, so it was not surprising that the craftsmen would select such blue pigment for creating Tongcao paintings, as they belonged to the export paintings of assembly line production. Besides,

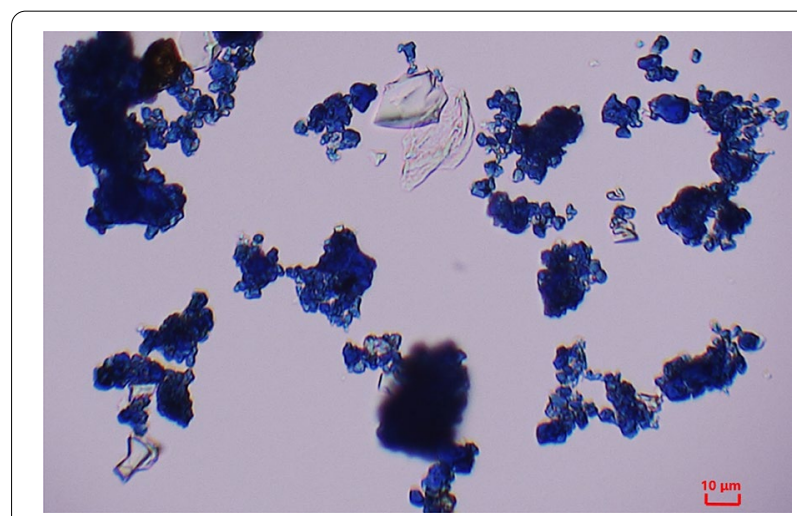

Fig. 5 The microscopic image of blue pigment (treated by absolute alcohol) under PLM

as its color was more gorgeous than azurite (a traditional Chinese precious mineral pigment), craftsmen in Guangzhou hence added it to their palette without hesitation. It originated in France and might be introduced into China by sea in late Qing Dynasty, and until 1927 Chinese chemist in Nanjing university successfully synthesized ultramarine blue [24].

\section{The green pigment}

The painting showed two kinds of green pigment: one was the bright green chair (Number 3), and the other was the dark green leaves (Number 11).

In the spectrum of green chair (Fig. 4e), serial Raman peaks of 106, 119, 152, 172, 216, 240, 291, 323, 370, 431, $492,538,681,755,842,950,1438$, and $1563 \mathrm{~cm}^{-1}$ were consistent with emerald green [20]. As a kind of artificial pigment, emerald green consisted of fine particle with high purities, which was first synthesized in 1814 [25] and was brighter and durable than copper carbonate used at that time. However, it tended to fade and blacken when exposed to an atmosphere containing hydrogen sulfide, and meanwhile, the arsenic inside emerald green $\left(\mathrm{Cu}\left(\mathrm{C}_{2} \mathrm{H}_{3} \mathrm{O}_{2}\right)_{2} \cdot 3 \mathrm{Cu}\left(\mathrm{AsO}_{2}\right)_{2}\right)$ would be easily separated out in the wet air,which made it extremely poisonous, so it was stopped to produce in 1950 [26].

Under microscopy, the dark green pigment was the mixture of blue particles, a few bright green particles and black particles. Figure 4g showed the Raman peaks of $278,536,2093$ and $2156 \mathrm{~cm}^{-1}$ of blue particles were consistent with prussian blue $\left(\mathrm{Fe}_{4}\left[\mathrm{Fe}(\mathrm{CN})_{6}\right]_{3}\right)$ [20], which could also explained the existence of high content $\mathrm{Fe}(2.39 \%)$ in dark green area by SED-EDS (Table 3), while two broad Raman peaks of 1336 and $1595 \mathrm{~cm}^{-1}$ referred to carbon black. In addition, the SEM-EDS analysis revealed that this area contained a small amount of $\mathrm{Cu}(0.49 \%)$ and As (0.26\%), so Raman peaks of 176, 217, 
Table 3 Semi quantitative analysis results of Number 11 by SEM-EDS

\begin{tabular}{|c|c|c|c|c|c|c|c|c|c|c|c|c|}
\hline Weight \% & $C$ & 0 & Al & $\mathrm{Si}$ & $S$ & $\mathrm{Cl}$ & $\mathrm{K}$ & $\mathrm{Ca}$ & $\mathrm{Fe}$ & $\mathrm{Cu}$ & As & $\mathrm{Pb}$ \\
\hline Area & 50.6 & 41.89 & 0.17 & 0.32 & 0.13 & 0.31 & 0.49 & 1.82 & 2.39 & 0.49 & 0.26 & 1.14 \\
\hline
\end{tabular}

369 and $952 \mathrm{~cm}^{-1}$ of green particles would be related to emerald green.

Prussian blue was a kind of synthetic blue pigment which had similar color with azurite. As early as 1704, Ghislain Diesbach revealed the manufacturing process of prussian blue, which was later introduced to painters as a blue pigment. Until the mid-18th century, it had been widely used in European oil painting [27]. According to documentary records, British east India Company had been exporting prussian blue from Britain to Guangzhou since 1775 [28]. Apparently, the clever craftsmen that time mixed the prussian blue, a few emerald green and a little carbon black to paint green leaves, which looked somewhat dark green and formed a different visual effect from green chair.

Results of Raman analyses of the above pigments could be summarized in Table 4:

As early as Nanyue Kingdom period (204-112 BCE), the connection had been established between Guangzhou and the world through the sea road, which could be reflected in the silver box of Persian style and the blue glasses from Western Asia that were excavated from the Western Han Nanyue kingdom mausoleum. Since Tang dynasty, Guangzhou had been regarded as one of the biggest harbor cities, which played an important role in promoting the cultural communication between China and western world. When it came to Ming \& Qing Dynasty, more and more European arrived and carried out all kinds of business activity in Guangzhou, which could be recorded by lots of historical documents. In this process, Chinese goods including ceramic, tea and silk were numerously shipped and sold to European Countries, and on the other hand, many goods such as oil painting, glass and pigments were imported into Guangzhou and other cities in China.

Since late Qing Dynasty, imported pigments began to be introduced into China at a large scale. At present, it was reported that synthetic ultramarine had been found in Mogao Grottoes of Gansu [29], Cizhong Catholic Church of Yunnan [22], Wuhou Memorial Temple of Chengdu [30] as a blue pigment of architectural painting, murals and painted sculpture. Emerald green, however, was mainly served as a decorative color of architectural painting in the process of construction and restoration. Besides the Cizhong Catholic Church mentioned above, archaeologists also found the use of emerald green in Drum Tower of Xi'an [31], Zhendu Men [32] and Wuying Hall [33] of the Imperial Palace in Beijing. Moreover, it was worth noting that a portrait painting of Taoism figure in late Qing Dynasty also used synthetic ultramarine and emerald green [34]. Compared with these pigments, the use cases of prussian blue seemed to focus on painting in China. It was reported that prussian blue was used in Zhenhai Tower [28], a Qing Dynasty oil painting for export, and glass paintings collected by Palace Museum [35] in Beijing.

These cases revealed that in late Qing Dynasty of China, craftsmen had consciously used imported synthetic pigments to partly replace traditional mineral pigments like azurite and malachite. As a kind of folk painting art at that time, pigments applied in Tongcao paintings also accorded with such development trend. The analytical result of pigments in our studies revealed both China's domestic mineral pigments and plant dyes, and western synthetic pigments, were applied in

\section{Table 4 Raman spectroscopy characteristics of pigments in different colors}

\begin{tabular}{|c|c|c|c|}
\hline Color & Raman shift $\left(\mathrm{cm}^{-1}\right)$ & Pigment identified & Detection points \\
\hline Black & 1324,1596 & Carbon black & Number 4 \\
\hline Yellow & $1431,1595,1627$ & Gamboge & Number 7, 8, 9 and 16 \\
\hline Blue & $259,548,808,1096,1355,1645$ & Ultramarine blue & Number 1, 2, $13 \& 15$ \\
\hline White & $153,280,711,1048,1085$ & Calcite and lead white & Number 6 and 10 \\
\hline Green (Bright) & $\begin{array}{l}106,119,152,172,216,240,291,323,370,431,492,538 \\
\quad 681,755,842,950,1438,1563\end{array}$ & Emerald green & Number 3 \\
\hline Green (Dark) & $176,217,278,369$, 536, 952, 1336, 1595, 2093, 2156 & $\begin{array}{l}\text { The mixture of prussian blue, emerald } \\
\text { green and carbon black }\end{array}$ & Number 11 \\
\hline Red & $121,151,223,314,389,548$ & Red lead & Number 5, 12 and 14 \\
\hline
\end{tabular}


the making process of this Tongcao paintings. We also discovered that multi-pigments with different concentration were mixed together to paint different areas in pursuing visual effect, which not only demonstrated the complexity of manufacturing process of Tongcao paintings, but also witnessed the arrival and application of western pigments in Guangzhou.

\section{Conclusion}

Analytical studies were helpful to disclose the materials, pigments and manufacturing technique of Tongcao paintings: (1) Microscopic study showed the cells of Tongcao pith were hexagonal and hollow, which were connected together through cell walls to form a relatively stable honeycomb structure, ultimately contributing to the stack of pigments and forming an uneven surface for the distribution of pigments, which might be the direct reason for strong stereoscopic effect of Tongcao painting. Meanwhile, The cells of historical Tongcao pith had started to degrade, which indicated an urgent requirement on conservation of Tongcao paintings. (2) The simulation experiment and SEM-EDS analyses revealed this Tongcao painting was supposed to be treated by alum up to 8 layers in the painting process, which confirmed the truth of Downing's travel notes. (3) Raman spectroscopy proved both China domestic pigments including red lead, calcite, lead white, carbon black and gamboge, and the synthetic pigments imported from Europe (synthetic ultramarine, prussian blue and emerald green) were applied in this painting, which not only witnessed the technical and commercial communication between China and the West, but was helpful to identify the production date of this painting was late Qing Dynasty, mainly the mid-late 19th century.

Our study highlighted the importance of Tongcao paintings in history and archaeology from a technological point of view, however, it was just a preliminary research to arouse the attention of academic community. As for the development process of materials, pigments and manufacturing technique of Tongcao paintings, more samples needed to be collected to conduct deeper and more systematically comparative studies.

\section{Acknowledgements \\ The authors would like to thank the institutions and individuals who assisted to the above experiments, especially professor Chen Jian and his assistant Yang Muzi of Confocal laser Raman microscopy laboratory in Sun Yat-sen University.}

\section{Authors' contributions}

CZ responsible for experiments of Microscopy, Raman Spectroscopy and SEM-EDS; JBH collecting literature and writing the paper; TQZ making deep interpretation basing on experimental data and literature; RLZ Assisting in sorting literature and other documents. All authors read and approved the final manuscript.
Funding

This research is supported by the National Science Foundation of China (No: 41103013).

\section{Availability of data and materials}

The datasets acquired are available from the corresponding author.

\section{Competing interests}

The authors declare that they have no competing interests.

\section{Author details}

${ }^{1}$ Research Center for Visual Culture, Guangzhou Academy of Fine Arts, Guangzhou 510006, China. ${ }^{2}$ The Opium War Museum, Humen 523900, China. ${ }^{3}$ College of Sociology \& Anthropology, Sun Yat-sen University, Guangzhou 510275, China. ${ }^{4}$ Southern Marine Science and Engineering Guangdong Laboratory (Zhuhai), Zhuhai 519000, China. ${ }^{5}$ The Joint Research Center of Maritime Silk Road (Nanhai I) by Sun Yat-sen University and Yangjiang Municipal People's Government, Yangjiang 529500, China. ${ }^{6}$ Guangzhou Thirteen Hongs Museum, Guangzhou 510130, China.

Received: 22 July 2020 Accepted: 6 December 2020

Published online: 25 January 2021

\section{References}

1. Crossman CL. The China trade: export paintings, furnitures, silver and other object. New York: Pyne Press; 1972.

2. Crossman CL. The Decorative Arts of the China Trade, Antique Collectors Club, 1991

3. Jiang YH. Western Painting and Canton Port During the Qing Period, Zhong Hua Book Company, 2007.

4. Cheng CJ. A study on Chinese Rice-paper painting of watercolors in the 19th century, Shanghai Classics Publishing House, 2008.

5. Arpo M. The Conservation of Chinese Export Painting on Pith Paper, quoted from Cheng CJ. A study on Chinese Rice-paper painting of watercolors in the 19th century, Shanghai Classics Publishing House, 2008, pp 46-47.

6. Holt JG. The Repair of Pith Paper Objects, quoted from Cheng CJ. A study on Chinese Rice-paper painting of watercolors in the 19th century, Shanghai Classics Publishing House, 2008, p 47.

7. Conner P, Yu YY. Guangzhou Thirteen Hongs: Foreign Merchants in Chinese Export Painting (1700-1900), Commercial Press, 2014.

8. Williams I, trans. \& ed. by Cheng MB. Created in Canton:Chinese Export Watercolors on Pith, Guangzhou: Lingnan Art Press, 2014.

9. Guangzhou Liwan District Bureau of Art Archive. Guangzhou Thirteen Hongs Museum. Pith paintings donated by Wang Heng and Feng Jie: Guangdong People's Press; 2015.

10. Zhu S, Wang Z, Wang G, et al. The Painting Manual of the Mustard Seed Garden. Beijing: China Bookstore; 1982.

11. Yin ZF, Fan RW. The study progress on the cell wall. Bull Botanical Res. 1999;19(04):407-14.

12. Wang HH, Wang CS. The influence of alum gelatin solution on the performance of traditional papers. China Cult Heritage Scientific Res. 2014;01:76-9.

13. Downing CT. The Fan-Qui in China, London: Henry Colburn, 1838, Vol.Il, p 97.

14. Smith GD, Clark RJH. Raman microscopy in archaeological science. J Archaeol Sci. 2004;31 (08):1137-60. https://doi.org/10.1016/j. jas.2004.02.008

15. Fu PG, Zheng HF. Raman Spectra of Aragonite and Calcite at High Temperature and High Pressure, Spectroscopy and Spectral Analysis, 2013; 33(06):1557-1561, http://dx.chinadoi.cn/10.3964/j. issn.1000-0593(2013)06-1557-05.

16. Bell IM, Clark RJH, Gibbs PJ. Raman spectroscopic library of natural and synthetic pigments (Pre 1850AD). Spectrochim Acta Part A Mol Biomol Spectrosc. 1997;53(12):2159-217. https://doi.org/10.1016/S1386 -1425(97)00140-6.

17. Si Y, Jiang HG, et al. Raman Microspectroscopic Analysis of Polychrome Wooden Artifact from the Astana Tomb of the Tang Dynasty, Xinjiang China. Spectroscopy Spectral Analysis. 2013;33(10):2607-11. 
18. Wang XF, Yu LK. The Manual of Mineral Color. Beijing: People's Fine Arts Publishing House; 2008.

19. Chang JJ. Study on the Raman spectroscopy of pigments and dyes in ancient murals, JiLin University, 2010.

20. Correia AM, Clark RJH, et al. Pigment study by Raman microscopy of 23 paintings by the Portuguese artist Henrique Pousão (1859-1884). J Raman Spectrosc. 2007;38:1390-405. https://doi.org/10.1002/jrs.1786.

21. Burgio L, Clark RJH, et al. Pigment Identification by Spectroscopic Means: evidence Consistent with the Attribution of the Painting Young Woman Seated at a Virginal to Vermeer. Anal Chem. 2005;77(05):1261-7. https:// doi.org/10.1021/ac048481i.

22. Zhu TQ, Chen J, et al. Spectroscopic Characterization of the Architectural Painting from the Cizhong Catholic Church of Yunnan Province China. Analytical Lett. 2013;46(14):2253-64. https://doi.org/10.1080/00032 719.2013.796559.

23. Xia Y. Chinese Historical Pigments in Polarized Light Microscope. Science Press, 2017, pp 42-43.

24. Dai $A B$, Ling $D Z$. The property and paper of artificial ultramarine. Jing Ling Coll. 1927;02:1271-83.

25. Eremin K, Stenger J, Huang JF, et al. Examination of pigments on Thai manuscripts: the first identification of copper citrate. Raman Spectroscopy. 2008;39:1057-65. https://doi.org/10.1002/jrs.1985.

26. Yu FA. Chinese Painting Colors: Studies of Their Preparation and Application in Traditional and Modern Times. Washington: University of Washington Press; 1988

27. Seldes AM, Burucúa JE, etc. Blue Pigments in South American Painting (1610-1780), Journal of the American Institute for Conservation, 1999; 38(02):100-123, https://doi.org/10.2307/3180041.

28. Wang B, Yu H, etc. Identification of pigments from "Zhenhai Temple", a Qing Dynasty export oil painting, Sciences of Conservation and Archaeology, 2017; 29(02): 82-88, http://dx.chinadoi.cn/10.16334/j.cnki. cn31-1652/k.2017.02.015
29. Wang JY. Study on synthetic ultramarine pigment from Mogao Grottoes, Dunhuang Research, 2000(01):76-81, http://dx.chinadoi.cn/10.13584 /j.cnki.issn1000-4106.2000.01.014.

30. Yang JS, Guo H, et al. A Scientific Study on the Craftsmanship and Pigments of Painted Sculptures from the Wuhou Memorial Temple in Chengdu City China. Cultural Heritage Sci Res. 2016;02:64-9.

31. Mazzeo R, Cam D, et al. Analytical study of traditional decorative materials and techniques used in Ming Dynasty wooden architecture. The case of the Drum Tower in Xi'an, P.R. of China. J Cultural Heritage. 2004;5(3):273-83

32. Cheng $X L$, Xia $Y$, et al. Three fabricated pigments (Han purple, indigo and emerald green) in ancient Chinese artifacts studied by Raman microscopy, energy-dispersive X-ray spectrometry and polarized light microscopy. J Raman Spectrosc. 2007;38:1274-9. https://doi.org/10.1002/ jrs.1766.

33. Shen $A G$, Wang $X H$, et al. Pigment identification of colored drawings from Wuying Hall of the Imperial Palace by micro-Raman spectroscopy and energy dispersive X-ray spectroscopy. J Raman Spectrosc. 2006;37:230-4. https://doi.org/10.1002/jrs.1435.

34. He QJ, Li T, et al. Non-destructive in situ characterization of pigments on a portrait of Chinese Taoism figure, Sciences of Conservation and Archaeology, 2010(03):61-68, https://doi.org/10.16334/j.cnki. cn31-1652/k.2010.03.020.

35. Yang B, Li GH, et al. Preliminary scientific analysis and research on colored glass painting from Imperial Palace of Qing Dynasty China. Cultural Heritage Sci Res. 2017;03:72-9.

\section{Publisher's Note}

Springer Nature remains neutral with regard to jurisdictional claims in published maps and institutional affiliations.

\section{Submit your manuscript to a SpringerOpen ${ }^{\circ}$ journal and benefit from:}

- Convenient online submission

- Rigorous peer review

- Open access: articles freely available online

- High visibility within the field

- Retaining the copyright to your article

Submit your next manuscript at $\boldsymbol{\nabla}$ springeropen.com 